\title{
Core Antrenmanının Yatay Sıçrama Performans Özelliğine Etkisi (Bir Meta-Analiz Çalışması)
}

\author{
Mehmet SÖYLER ${ }^{1}$, İdris KAYANTAȘ² ve Mehmet GÜNAY ${ }^{3}$
}

Öz

Bu çalışmada; YÖK tez merkezi web sitesinden yayınlanmış lisansüstü tezlerden tarama usulüyle elde edilen veriler neticesinde deneysel yöntemlerle core antrenmanının yatay sıçrama performansı üzerine etkisinin araştırıldığı çalışmaların etki büyüklüklerinin birleştirilmesi ve sonuçlarının bu birleştirme yöntemiyle bir bütün olarak ortaya konması amaçlanmıştır. Araştırmaya alınacak çalışmaların belli kriterler dâhilinde olmaları göz önünde bulundurulmuştur. Deneysel meta analizde Comprehensive Meta Analysis (CMA) programından faydalanılmıştır. Heterojenlik testininin verilerine göre istatistiğin rastgele etkiler modeline göre düzenlenmesi gerekmektedir. Çalışmada hem sabit etkiler hem de rastgele etkiler modeli sonuçlarına yer verilmiştir. Yaptığımız bu çalışmanın metaanaliz verilerine göre, core antrenmanının yatay sıçrama performansı üzerine etkisine bakıldığında sabit etkiler modeline göre 0,372 ile küçük düzeyde, rastgele etkiler modelinde ise 0,473 etki büyüklüğüyle orta düzeyde olduğu tespit edilmiştir. Yatay sıçrama özelliğinin gelişimi için, core antrenmanlarının orta düzeyde etkili olduğu tespit edilmiştir. Core antrenmanının yatay sıçrama performansı üzerine etsini meta-analiz yöntemiyle etki büyüklügüünü ortaya koyan Türkiye'de daha önce yapılmış herhangi bir araştırmaya rastlanmamıştır. Bu yüzden literatüre önemli katkilar sağlayacağı düşünülmektedir.

Anabtar Kelimeler: Core, Antrenman, Core antrenman, Meta-analiz

\section{Effect of Core Training on Horizontal Jump Performance (A Meta-Analysis Study)}

\begin{abstract}
In this study; as a result of the data obtained by scanning method from postgraduate theses published on The Council of Higher Education thesis center website, it is aimed to combine the effect sizes of the studies that examined the effect of core training on the horizontal jump performance and to reveal the results as a whole with this combination method. It has been taken into consideration that the studies to be included in the study meet certain criteria. These criteria are being a postgraduate thesis, including experimental and control groups, pretest and posttest data were taken, arithmetic means, standard deviation data are included. Studies without these criteria are not included in this study. Comprehensive Meta-Analysis (CMA) program was used in experimental meta-analysis. According to the heterogeneity test, analysis should be done according to random effects model and in case of high heterogeneity, moderator analysis should be done. In our study, since the heterogeneity rate was high, the results of the type of broadcasting and the duration of the training were included in the moderator analysis. In the study, both fixed effects and random effects model results are included. As a result, according to the meta-analysis data of our study, when the effect of core training on horizontal jump performance is examined, it is determined that it is small with 0.372 according to the fixed effects model, and moderate with 0,473 effect size in the random effects model. Core training has been determined to be moderately effective for the development of the horizontal jump feature. There has not been any study observed in Turkey about Core horizontal jump the effects on performance of training performed meta-analysis demonstrating the effect size. Thus, it is considered that it will make important contributions to the literature.
\end{abstract}

Key Words: Core, Training, Core training, Meta-analysis

\section{Atıf İçin / Please Cite As:}

Söyler, M., Kayantaş, İ. ve Günay, M. (2020). Core antrenmanının yatay sıçrama performans özelliğine etkisi (Bir meta-analiz çalışmas1). Manas Sosyal Araștırmalar Dergisi, 9(4), 2560-2567.

Geliş Tarihi / Received Date: 30.05.2020

Kabul Tarihi / Accepted Date: 27.07.2020

\footnotetext{
${ }^{1}$ Dr . Ögr. Gör.-Türkiye Çankırı Karatekin Üniversitesi Yapraklı Meslek Yüksekokulu, mehmetsoyler@karatekin.edu.tr ORCID:0000-0002-6912-4218

2 Dr. Ögr. Gör. Türkiye Bingöl Üniversitesi Beden Eğitimi ve Spor Yüksekokulu, ikayantas@bingol.edu.tr ORCID: 0000-0001-9644-9387

3 Prof. Dr - Türkiye Gazi Üniversitesi Spor Bilimleri Fakültesi, mgunay@gazi.edu.tr ORCID:

0000-0003-0047-2203
} 


\section{Giriş}

Core antrenman belli bir kas veya hedef kas etkinliğine yönelik farklı bir şekilde hazırlanmış antrenmanlar olarak tanımlanmaktadır. Core kasları abdominaller, alt ve sırt bölgesinin kaslarından meydana gelmektedir. Tüm karın kasları, vücudun dorsal kas bölgesinin sağlık açısından günlük egzersizlerin yanında fitness antrenmanları esnasında omurgayı sabitlemede de önemli bir role sahiptirler. Core antrenmanları sayesinde vücudumuzun kontrolünü sağlayabilir ve denge gelissimine yardımc1 olabiliriz. Birden çok hem büyük hem de küçük kas grubunun kuvvetlenmesiyle sakatlık faktörünü azaltabilir ve denge gelişimine yönelik olarak aktiviteler ya da hareketler arası geçiş için rantabilitede artırabilir. (Herrington ve Davies 2005). Core kasları vücudun ve kalça kemiğinin dengesinin sağlamasına ve omuriliği sabitlenmesinde önemli bir rol oynarlar (Akothota vd., 2008). Bununla birlikte vücudun bir bütün olarak sergilediği etkin bir hareket esnasında core kaslarının nasıl davrandığının anlaşılması gereklidir. Yani core bölgesinde maksimum seviyede yüklenme ve buna bağlı olarak gelişme sağlanması için core kaslarının yapı ve karakterinin iyi bilinmesi gerekmektedir (Willardson, 2014).

Core bölgesinin stabilitesini ve kuvvetini artırarak, sporcuların sahip oldukları kuvveti sağlıklı bir şekilde güce aktarabildikleri görülmektedir. Teknik gelişimde meydana getirdiği gelişim ile core antrenman; sporcuların becerilerini minimum enerji sarf ederek yapılmasına imkân sağlar. Sonuç olarak, sporcular uzun süre yorgunluğun etkilerini daha az hissedeceklerdir (Şatıroğlu vd., 2013).

Sporcu performans açısından değerlendirildiğinde; vücudun alt ve üst bölgelerinin hareketlerine katk1 sağlamaktadır. Fonksiyonel çalışmalarda, yavaşlama, denge ve stabilizasyon, ivmelenme, iyi antrene edilmiş bir core bölgesi yoluyla elde edilmektedir. Core kaslarının aktive edilmesi ve iyi duruma getirilmesi ile birçok kas-iskelet sistemi sakatlığın oluşmasında ve iyileştirilmesinde sportif performansın yükseltilmesi amaçlanmaktadır. Amacına uygun çalıstırılmış core kaslarının en uygun gücü ortaya koyduğu gibi, fonksiyonel sporcu performans için, gücün ve hareketlerin bağlantısına zemin hazırladığı da düşünülmektedir (Kibler vd. 2006).

Meta-analiz, farklı araştırmacılar tarafından benzer konular üzerinde yapılımış çalışmaların sayısal verilerini göz önünde bulundurarak, bu verilerin istatistiksel analizini yapma ve elde edilen sonuçlara dayanarak genel bir sonuca ulaşma yöntemidir (Sağlam ve Yüksel, 2007). Meta-analiz çalışmasının bilimsel olarak temel amacı, farklı mekânlarda ve zamanlarda elde edilen verileri bir araya getirerek yeniden yorumlamaktır (Yıldız, 2002). Günümüzde eğitim alanında yapılan bilimsel çalışmaların sayısının hızla artmaktadır. Bir çalış̧ma yapmak isteyen araştırmacının bütün alan yazınlarını incelemesi, elde edilen sonuçları gözden geçirmesi ve önerileri dikkate alması zorlaşmakta, araştırmacının çok fazla zaman harcamasını gerektirmekte ve istenilen bilgiye ulaşmasını zorlaştırmaktadır (Sağlam ve Yüksel, 2007).

\section{Yöntem}

Yapılan bu çalışmada meta-analize dayalı yöntem kullanılmıştır. Meta-analiz yönteminin kullanılmasının esas sebeplerinden biri core antrenmanı ile ilgili yapılmış araştırmaların bulgularını birleştirerek core antrenmanlarının yatay sıçrama üzerine genel etkililiği hakkında genel bir yargı̀a varmak amaçlanmıştır. Bu yöntemde, deneysel araştırma sonuçları analiz edilerek araştırmacılara nicel veriler sunulmakta; tüm çalışmaların sonuçları toplanarak genel bir sonucun belirlenmesi ve çalışmanın istatistiksel anlamlılık düzeyinin artırılarak sonuçlar hakkında daha kesin ifadelere ulaşılması sağlanabilmektedir (Dinçer, 2014; Sağlam ve Yüksel, 2007). Meta-analiz aynı zamanda yapılmış olan araştırmalarda core antrenmanının verimlilik ilişkisi arasında farklılı̆̆ın var olması ya da olmamasını da ortaya koymaktadır. Bir alanda yapılmış birden fazla çalışmanın sonuçlarının toplanarak araştırılması, örtüşen sonuçları sağlayan diğer çalışmaların geçerliliğini artırabilmesi, meta-analiz çalışmalarının belirgin özelliği olarak değerlendirilmektedir (Abramson ve Abramson, 2001; Sağlam ve Yüksel, 2007).

\section{Veri Toplama Araçları}

Araşıırma için YÖK Tez (Ulusal Tez Merkezi) 'de yayınlanmış yüksek lisans ve doktora tezlerinden yararlanılmışır. Tezler "antrenman, core antrenmanı, core, core egzersizleri”" anahtar kelimeleriyle literatür taraması yapılmıştır. Anahtar kelimelerle taranan araştırma ile ulaşılan çalışmalar, analizle orantılı ve elverişli veriler içeriyorsa meta-analiz yöntemine dâhil edilmiştir. Seçim kriterleri şunlardır:

- Core antrenmanı çalışılmış lisansüstü tezler,

- YÖK ulusal tez merkezinde yayımlanmış doktora ve yüksek lisans tezleri, 
- Yapılan çalışmalarda kontrol ile deney gruplarının varlığı,

- Örneklem büyüklükleri, standart sapma ve aritmetik ortalamalarının olması temel alınmıştır.

$\mathrm{Bu}$ tezler deneysel araştırmalara odaklanılarak özellikle deney ve kontrol grupları bulunan, ön değerlendirme testi ve son değerlendirme testi şeklinde uygulanan, aritmetik ortalama, standart hatası hesaplanmış tezler ilgili araştırma için seçilmiştir. Bahsedilen ölçütleri sağlamayan araştırmalar elenmiştir. Yukarnda belirtilen anahtar kelimeler sonucunda 72 adet doktora ve yüksek lisans tezi tespit edilmiştir. $\mathrm{Bu}$ tezler içerisinden yatay sıçrama çalışılmış toplam 10 yüksek lisans, 2 adet doktora tezi ile birlikte totalde 12 adet lisansüstü tez ile birlikte örneklem sayısının 415 olduğu görülmüştür. Araştırma kapsamında yer alan araştırmalar Microsoft Excel programında bir veri analiz dokümanına kaydedilmiştir.

\section{Verilerin Analizi}

Araştırmada deneysel meta analiz yöntemi kullanılmıştır. Deneysel meta-analizde Comprehensive Meta Analysis (CMA) programından yararlanılmıştır. Etki büyüklügünün deney ve kontrol gruplarına bağlı olarak hesaplandığı bu analizde etki büyüklüğü, gruplar arasındaki ortalama fark anlamına gelmektedir (Malofeeva, 2005 Akt: Çelik, 2013, s. 58). Meta analiz sonucunda elde edilen etki büyüklüklerinin sınıflandırması aşağıda Cohen'in sınıflandırma ölçeğine göre yapılmıştır.

Tablo 1. Cohen'in Etki Büyü̈klïğ̈̈nü Sinflanderma Ölçeği (Cohen,1988)

\begin{tabular}{cccc}
\hline$-0.15 \leq \mathrm{d}<0.15$ & Önemsiz düzeyde & $0.75 \leq \mathrm{d}<1.10$ & Geniş düzeyde \\
$0.15 \leq \mathrm{d}<0.40$ & Küçük düzeyde & $1.10 \leq \mathrm{d}<1.45$ & Çok geniş düzeyde \\
$0.40 \leq \mathrm{d}<0.75$ & Orta düzeyde & $1.45 \leq \mathrm{d}$ & Mükemmel düzeyde \\
\hline
\end{tabular}

\section{Bulgular}

\section{Yayın Yanlılı̆̆1 Bulguları}

Bu çalışmada yayın yanlllığı huni saçılım grafiği ve Orwin' in Hata Koruma Sayısı N (Orwin's Fail Safe N) sonuçlarına göre test ölçülmüştür. Çalışmada yayın yanlılı̆ıının olmaması, çalışmaya dâhil edilen araştırmaların, birleştirilmiş etki büyüklüklerini gösteren dikey çizgiye bağlı her iki tarafındaki simetrik bir şekilde dağllımları beklenmektedir (Borenstein vd., 2009, s. 284). Şekil 1'de huni saçılım grafiği sunulmuştur.

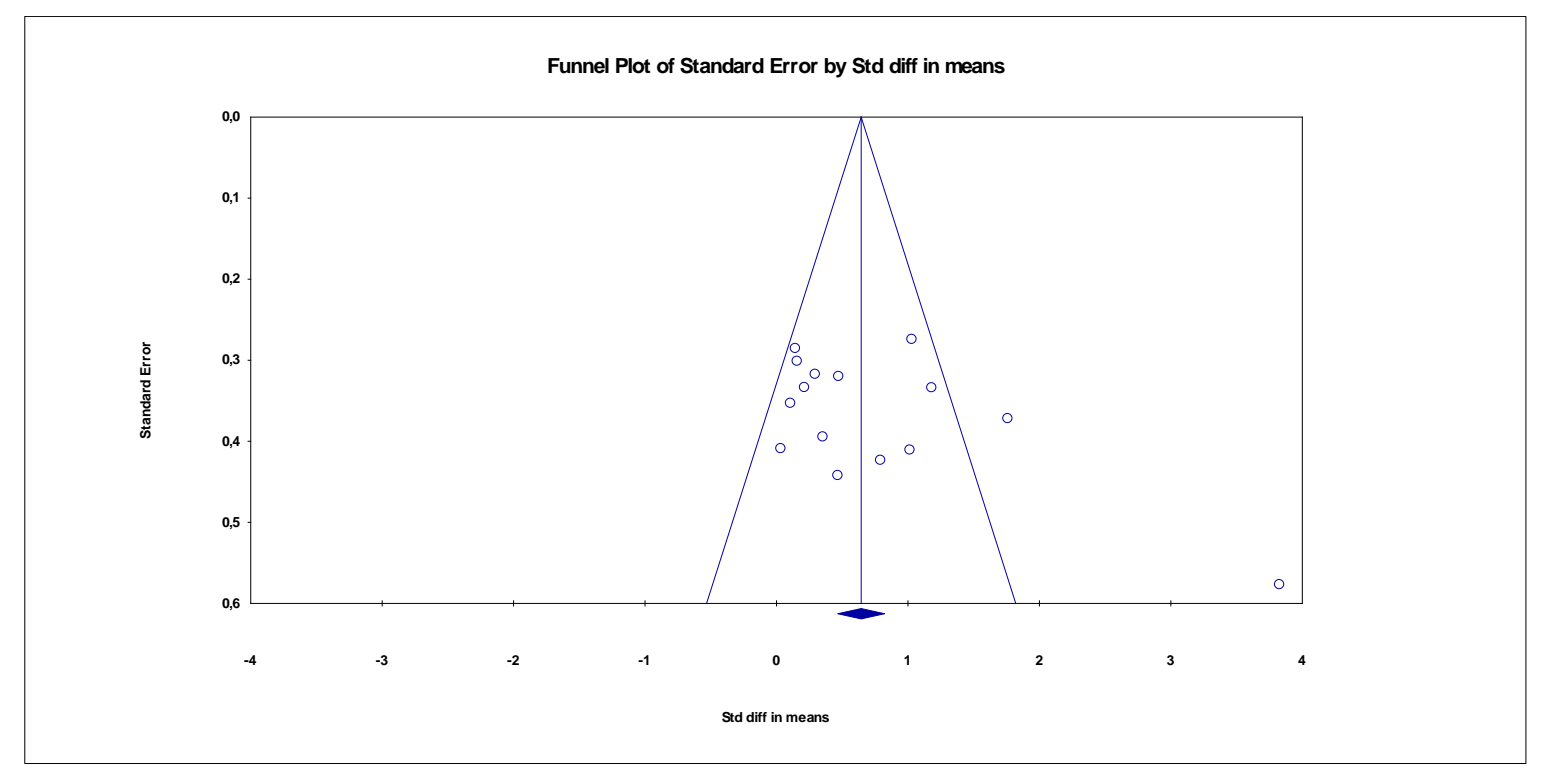

Şekil 1. Huni Saçllm Grafiüi

Çalışma içerisine alınan bu 12 çalışmada yayın yanlılı̆̆ının varlığı olmuş olsaydı, araştırmaların çoğunluğu huni grafiğinin alt bölümünde ya da dikey çizginin yalnızca bir bölümünde toplanmış olması söz konusu olurdu. Şekil 1 incelendiğinde çalışmaların nerdeyse hepsi huni içerisinde yer almakta ve ortalama etki büyüklüğü çevresinde neredeyse simetrik bir dağılım gösterdiği görülmektedir. Bu sonuca göre yayın yanlılığı olmadığı söylenebilir. 
Yayın yanlılı̆̆ını değerlendirmede diğer bir yöntem olan Orwin’ in Hata Koruma Sayısı N testine ait sonuçlar aşağıda gösterilmiştir.

Tablo 2. Orwin'in Hata Koruma Sayısı N Sonuclar

\begin{tabular}{ll}
\hline Element & Değerler \\
\hline Gözlemlenen Çalışmalarda Std. Ort. Farklılı̆̆1 & 0,37162 \\
“Önemsiz” Değeri için Std. Ort. Farklıı̆ıı & 0,01000 \\
Kayıp Çalışmalarda Std. Ort. Farklılığı Ortalaması & 0,00000 \\
Std. Ort. Farklılığı 0,01’in altında bir değere getirmek için gerekli çalışma sayısı & 434,000 \\
\hline
\end{tabular}

Tablo 2 incelendiğinde meta analize dâhil edilen 12 çalşmaya ait ortalama etki büyüklüğü değerini neredeyse önemsiz düzeye düşürecek çalışma sayısının 434 olduğu görülmektedir. Bu 12 çalsşmaya ek olarak Türkiye'de bu konuda yapılmış 434 çalışmaya daha ulaşılmasının söz konusu olmadığı düşünülmektedir. Bu nedenle bu sonuca göre çalışmada yayın yanlılığı olmadığı söylenebilir.

Tablo 3. Heterojenlik Testi

\begin{tabular}{cccc}
\hline$\chi^{2}$ & P- Değeri & $\mathrm{I}^{2}$ \\
\hline 40,376 & 11,000 & 0,000 & 72,756
\end{tabular}

Tablo 3 incelendiğinde, çalışmaların sabit etkiler modeline göre $Q$ istatistiksel değerinin 40,376 olduğu görülmektedir. Bu değer 11 serbestlik dereceli ki-kare $(\chi 2)$ değerinden $(19,675)$ büyük olduğu ve etki büyüklükleri sabit etkiler modeli altında orta düzeyde heterojen bir dağıllım göstermektedir. Bu nedenle yaş ve antrenman süresine ait moderatör analiz sonuçları aşağıda gösterilmiştir. Q istatistiğinin bir diğer tamamlayıcısı olarak geliştirilen $\mathrm{I}^{2}$ ise heterojenliğe yönelik daha net bir sonuç ortaya koymaktadır (Petticrew ve Roberts, 2006; Yıldırım, 2014). I² etki büyüklügüne yönelik toplam varyansın oranını göstermektedir. $\mathrm{I}^{2}$ istatistiği $\mathrm{Q}$ istatistiğinin tersi yönde çalışma sayısından etkilenmemektedir. $\mathrm{I}^{2}$ 'nin yorumlanmasında ise $\% 25$ düşük düzeyde heterojenliğgi, \% 50 orta düzeyde heterojenliği ve $\% 75$ yüksek düzeyde heterojenliği göstermektedir (Cooper vd., 2009, s. 263). Dikey sıçrama değişkeni için yapılan homojenlik testleri (Q ve $\left.I^{2}\right)$ sonucunda çalısmalar arasında yüksek düzeyde $(72,756)$ heterojenlik bulunduğundan birleştirme işlemi için model rastgele modele çevrilmiştir. Bu heterojenliğin nedenlerini ortaya koyabilmek için yapılan moderatör analizi sonuçları (Fixed Effect Analysis) aşağıda verilmiştir.

Tablo 4. Calıșmalarm Sabit ve Rastgele Etkiler Modellerine Göre Birleştirilmiş Bulgular

\begin{tabular}{|c|c|c|c|c|c|c|c|c|}
\hline & $\mathbf{N}$ & $\begin{array}{c}\text { Etki } \\
\text { Büyüklüğüu }\end{array}$ & S.Hata & Varyans & $\begin{array}{c}\text { Alt } \\
\text { Sinır }\end{array}$ & $\begin{array}{c}\text { Üst } \\
\text { Sinır }\end{array}$ & $\begin{array}{c}\text { Z- } \\
\text { Değgeri }\end{array}$ & $\begin{array}{c}\text { P- } \\
\text { Değgeri }\end{array}$ \\
\hline Sabit Etkiler & 12 & 0,372 & 0,102 & 0,010 & 0,172 & 0,571 & 3,650 & 0,000 \\
\hline Rastgele Etkiler & 12 & 0,473 & 0,200 & 0,040 & 0,081 & 0,864 & 2,367 & 0,018 \\
\hline
\end{tabular}

Sabit etkiler modeline göre meta-analize dâhil edilen 12 çalısmaya ait ortalama etki büyüklüğü \%95 güven aralığında üst sınırı 0,571 ve alt sınırın 0,172 ile ortalama etki büyüklüğü değerinin 0,372 olduğunu göstermektedir ( $\mathrm{z}=3,650 ; \mathrm{p}=0,000)$. Bu değer Cohen (1988) sınıflandırmasına göre küçük düzeyde etki büyüklüğü aralığında yer almaktadır.

Rastgele etkiler modeline göre meta-analize dâhil edilen 12 çalısmaya ait ortalama etki büyüklüğü \% 95 güven aralığında üst sinırı 0,864 ve alt sınırı 0,081 ile ortalama etki büyüklüğü değerinin 0,473 olduğunu göstermektedir ( $\mathrm{z}=2,367 ; \mathrm{p}=0,018)$. Bu değer Cohen (1988) sınıflandırmasına göre orta düzeyde etki büyüklüğü aralı̆̆ında yer almaktadır.

Sabit etkiler ve rastgele etkiler modeline göre birleștirilen çalışmaların ortalama etki büyüklüğü değeri Cohen (1988) sınıflandırmasına göre sabit etkiler modelinde düşük düzeyde, rastgele etkiler modelinde ise "orta düzeyde" olduğu tespit edilmiştir. Bu sonuç; core antrenmanının sporcuların yatay sıçrama özelliğini geleneksel yöntemlere kıyasla orta düzeyde etkilediğini göstermektedir. 
Grafik 1. Callsmalarn Rasgele Etkiler Modeline Ait Orman Grafiugi

\begin{tabular}{|c|c|c|c|c|c|c|c|c|c|c|c|}
\hline \multirow[t]{2}{*}{ Study name } & \multicolumn{7}{|c|}{ Statistics for each study } & \multicolumn{4}{|c|}{ Std diff in means and $95 \% \mathrm{Cl}$} \\
\hline & $\begin{array}{l}\text { Std diff } \\
\text { in means }\end{array}$ & $\begin{array}{l}\text { Standard } \\
\text { error }\end{array}$ & Variance & $\begin{array}{l}\text { Lower } \\
\text { limit }\end{array}$ & $\begin{array}{l}\text { Upper } \\
\text { limit }\end{array}$ & Z-Value & $p$-Value & & & & \\
\hline ozgul, 2019 & 0,001 & 0,354 & 0,125 & $-0,692$ & 0,694 & 0,003 & 0,998 & & & & \\
\hline dedecan, 2016 & 0,728 & 0,422 & 0,178 & $-0,098$ & 1,554 & 1,727 & 0,084 & & & & \\
\hline ozdogru,2018 & $-0,197$ & 0,259 & 0,067 & $-0,704$ & 0,310 & $-0,762$ & 0,446 & & & & \\
\hline bas, 2018 & 0,504 & 0,321 & 0,103 & $-0,126$ & 1,133 & 1,568 & 0,117 & & & & \\
\hline bilici,2018 & 2,075 & 0,425 & 0,181 & 1,242 & 2,909 & 4,878 & 0,000 & & & & \\
\hline sever,2016 & 0,032 & 0,410 & 0,168 & $-0,771$ & 0,835 & 0,079 & 0,937 & & & & \\
\hline barak, 2019 & 1,309 & 0,340 & 0,116 & 0,642 & 1,975 & 3,849 & 0,000 & & & & \\
\hline civan, 2019 & 0,086 & 0,258 & 0,067 & $-0,420$ & 0,593 & 0,334 & 0,738 & & & & \\
\hline aydin, 2019 & 0,277 & 0,410 & 0,168 & $-0,527$ & 1,080 & 0,674 & 0,500 & & & & \\
\hline aslan, 2014 & $-0,354$ & 0,375 & 0,140 & $-1,088$ & 0,380 & $-0,944$ & 0,345 & & & & \\
\hline dikici,2018 & 1,522 & 0,568 & 0,322 & 0,409 & 2,635 & 2,681 & 0,007 & & & & \\
\hline \multirow[t]{3}{*}{ kir,2017 } & 0,245 & 0,379 & 0,144 & $-0,499$ & 0,988 & 0,645 & 0,519 & & & & \\
\hline & 0,473 & 0,200 & 0,040 & 0,081 & 0,864 & 2,367 & 0,018 & & & & \\
\hline & & & & & & & & $-4,00$ & $\begin{array}{c}-2,00 \\
\text { Kontrol Grubu }\end{array}$ & $\begin{array}{c}2,00 \\
\text { Deney Grubu }\end{array}$ & 4,00 \\
\hline
\end{tabular}

Tablo 5. Antrenman Süresi Moderatörüne Ait Bulgular

\begin{tabular}{|c|c|c|c|c|c|c|c|c|}
\hline $\begin{array}{l}\text { Antrenman } \\
\text { Süresi }\end{array}$ & $\mathbf{N}$ & $\begin{array}{c}\text { Etki } \\
\text { Büyüklüğ̈̈ }\end{array}$ & S. Hata & $\begin{array}{l}\text { Üst } \\
\text { Sinır }\end{array}$ & $\begin{array}{l}\text { Alt } \\
\text { Sinur }\end{array}$ & $\begin{array}{c}\text { Q- } \\
\text { Değeri }\end{array}$ & $\mathrm{df}(\mathrm{Q})$ & $\begin{array}{c}\text { P- } \\
\text { Değeri }\end{array}$ \\
\hline $10 \mathrm{Hafta}$ & 4 & 0,481 & 0,290 & $-0,087$ & 1,050 & 9,430 & 3,000 & 0,024 \\
\hline 8 Hafta & 8 & 0,482 & 0,284 & $-0,074$ & 1,038 & 30,537 & 7,000 & 0,000 \\
\hline & & & & \multirow{2}{*}{\multicolumn{2}{|c|}{$\begin{array}{c}\text { Grup içi } \\
\text { Gruplar aras1 }\end{array}$}} & 39,966 & 10,000 & 0,000 \\
\hline & & & & & & 0,000 & 1,000 & $0,998 *$ \\
\hline
\end{tabular}

Tablo 5 incelendiğinde; 10 hafta antrenman süresine sahip çalş̧aların etki büyüklüğü değeri $0,481 \%$ 95 güven aralığında alt sınırın 1,050, üst sınırın $-0,087$ olduğu, 8 hafta antrenman süresine göre yapılan çalışmaların etki büyüklüğü değeri $0,482(\% 95)$ güven aralığında alt sinırın 1,038 üst sınırın $-0,074$ olduğu görülmektedir. Bu sonuca göre 10 hafta ve 8 haftalık core antrenman süresinin yatay sıçrama performansı üzerine etkisinin çok ta değiştirmediğini göstermektedir. Gruplar arasında bu etki büyüklüğü değerleri istatiksel olarak anlamlı bir farklilık göstermemektedir.

Tablo 6. Yaymn Türü Moderatörüne Ait Bulgular

\begin{tabular}{|c|c|c|c|c|c|c|c|c|}
\hline Yayın Türü & $\mathbf{N}$ & $\begin{array}{c}\text { Etki } \\
\text { Büyüklüğg̈ }\end{array}$ & S.Hata & $\begin{array}{c}\text { Alt } \\
\text { Sinir }\end{array}$ & $\begin{array}{l}\text { Üst } \\
\text { Sinir }\end{array}$ & Q-value & df $(Q)$ & P-value \\
\hline Doktora Tezi & 2 & 1,650 & 0,381 & 0,903 & 2,396 & 1,981 & 1,000 & 0,159 \\
\hline Yüksek Lisans & 10 & 0,189 & 0,136 & $\begin{array}{c}-0,078 \\
\text { Grup içi } \\
\text { Gruplar arasi }\end{array}$ & 0,455 & $\begin{array}{l}13,011 \\
14,991 \\
13,053\end{array}$ & $\begin{array}{c}9,000 \\
10,000 \\
1,000\end{array}$ & $\begin{array}{c}0,162 \\
0,132 \\
0,000^{*}\end{array}$ \\
\hline
\end{tabular}

Tablo 6 incelendiğinde; doktora tezine ait çalısmaların etki büyüklüğü değeri 1,650\%95 güven aralığında alt sınırın 0,903 , üst sınırın 2,396 olduğu, doktora tezine ait çalışmaların etki büyüklügü değeri 0,189 (\% 95) güven aralığında alt sınırın -0,078 üst sınırın 0,455 olduğu görülmektedir. Bu sonuca göre doktora tezi çalışmalarının etki büyüklüğü değeri mükemmel düzeyde iken, yüksek lisans tezlerinin etki büyüklüğü küçük düzeydedir. Ve gruplar arası anlamlı bir farklılık olduğu görülmektedir.

\section{Tartışma, Sonuç ve Öneriler}

Core antrenmanının yatay sıçrama performansı üzerine etkisini inceleyen farklı çalışmaların verilerinin birleştirerek yaptı̆̆ımız bu çalışmanın meta-analiz çalışmasının sonuçlarına göre, core antrenmanının yatay sıçrama performansı üzerine etkisine bakıldığında çok önemli bir değişim meydana getirmediği tespit edilmiştir. Sabit etkiler modeline göre 0,372 ile küçük düzeyde, rastgele etkiler modelinde ise 0,473 etki büyüklüğüyle orta düzeyde etki büyüklüğü olduğu görülmüsstür.

Boyacı vd. (2018) 11-13 yaş arası futbolcularda yapılan 10 haftalık core antrenman antrenmanının fiziksel performansa etkisinin incelemeleri sonucunda core antrenman deney grubunun, durarak uzun atlama testlerinde olumlu yönde gelişme olduğunu ortaya koymuşlardır.

Civan (2019) yaptıkları çalışmaya 30 deney 30 kontrol grubu sporcu katılmıstır. 8 hafta uygulanan core egzersizleri sonucunda deney grubunda ön test ve son test değerlerinin karşlaş̧tırılmasında, durarak 
uzun atlama ve diğer performans değerleri arasında istatistiksel olarak anlamlı bir farkllllk olduğu görülmüştür $(\mathrm{P}<0,05)$.

Aydın (2019) Çalışmasında denek grubunun durarak uzun atlama ön test ve son test ortalamaları arasında $(4,8 \mathrm{~cm}$.) lik bir artş̧la anlamlı bir farklılık olduğunu tespit etmiştir $(\mathrm{p}<0,05)$.

Boyacı (2016) 12-14 yaş grubu futbolcularda yapılan 12 haftalık merkez bölge (core) antrenman programı sonucunda, durarak uzun atlama performansı olumlu yönde geliştiğini bildirmiştir.

Dedecan (2016) Erkek öğrenciler üzerinde merkez bölge (core) egzersizlerinin bazı fiziksel ve fizyolojik özellikleri üzerine etkisini araştırmıss, denek grubu ve kontrol grubunun durarak uzun atlama parametrelerinde gruplar arasında anlamlı farklilık olduğunu tespit etmiştir.

TSE vd. (2005) Merkez bölge (core) dayanıklılık antrenmanlarını kürek sporcuları üzerinde uygulamış ve 8 haftalık antrenman programı boyunca haftada 2 gün uygulatılan core dayanıklilık antrenman programı sonucunda durarak uzun atlama performanslarında anlamlı değişim görülmediğini söylemiştir.

Aslan (2014) yaptığı araştırmada; genç futbolculara uygulamış olduğu 8 haftalık core antrenman programı sonucunda non-dominant bacak durarak uzun atlama performansı ve üçlü sıçrama mesafesi artış gösterdiğini ancak, bu iki parametreye ait antrenman öncesi - sonrası fark ortalamalarının deney ve kontrol grupları arasında farkl1lık göstermemiştir.

\section{Etik Beyan}

“Core Antrenmanının Yatay Sıçrama Performans Özelliğine Etkisi (Bir Meta-Analiz Çalışması)” başlıklı çalışmanın yazım sürecinde bilimsel, etik ve alıntı kurallarına uyulmuş; toplanan veriler üzerinde herhangi bir tahrifat yapılmamış ve bu çalışma herhangi başka bir akademik yayın ortamına değerlendirme için gönderilmemiştir.

\section{Kaynakça}

Yıldız imi $\left(^{*}\right)$ meta-analize dâhil edilen çalşmaları göstermektedir.

*Aslan, A. K. (2014). Genc futbolcularda sekiz haftallk. "core" antrenmann denge ve fonksiyonel performans üzerine etkisi (Yüksek Lisans Tezi). Selçuk Üniversitesi Sağlık Bilimleri Enstitüsü, Konya.

*Aydın, A. S. (2019). 13-15 yas badminton sporcularna uygulanan sekiz baftalke "core" antrenmanlarn denge, kas kuvveti, sürat ve çeviklike performanslarn üzerine etkisinin incelenmesi (Yüksek Lisans Tezi). İstanbul Gelişim Üniversitesi Sağllk Bilimleri Enstitüsü, İstanbul.

*Barak, R. (2019). Periyotlanmis kor egzersizlerinin genc voleybolcularda bazt motorik özellikler ile servis hrz, ve isabet oranna etkisi (Yüksek Lisans Tezi). Bartın Üniversitesi Sosyal Bilimler Enstitüsü, Bartın.

*Baş, M. (2018). 11-13 Yas grubu futbolculara uygulanan 10 baftalle core antrenmann seģili motor parametrelere etkisinin değerlendirilmesi (Yüksek Lisans Tezi). İstanbul Gelişim Üniversitesi Sağlık Bilimleri Enstitüsü. İstanbul.

*Bilici, Ö. F. (2018). Core (kor) antrenmanlarmin 14-16 yas grubu kadn voleybolcularn sıcrama kuvveti ve baž motorik özellikleri ürerine etkisinin değerlendirilmesi (Yüksek Lisans Tezi). Van Yüzüncü Yıl Üniversitesi Eğitim Bilimleri Enstitüsü, Van.

*Civan, A. H. (2019). 10-12 yas futbolcularda 8 baftalık kor antrenmanlarn sürat, seviklike ve denge üzerine etkisi (Yüksek Lisans Tezi). Selçuk Üniversitesi. Sağllk Bilimleri Enstitüsü, Konya.

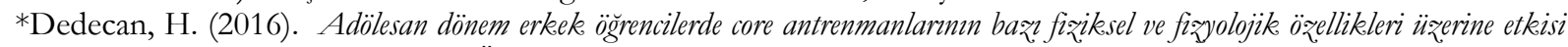
(Yüksek Lisans Tezi). Selçuk Üniversitesi Sağlık Bilimleri Enstitüsü, Konya.

*Dikici, S. (2018). Spor yapan ortaöğretim çağındaki ögrencilerde core antrenman modelinin ögrencilerin fižyolojik parametrelerine etkisi (Yüksek Lisans Tezi). Kahramanmaraş Sütçü İmam Üniversitesi Sağllk Bilimleri Enstitüsü, Kahramanmaraş.

*Kır, R. (2017). 11-15 yas arası tenis sporcularnda kor antrenman programmnn kuvvet, sürat, çeviklike ve denge üzerindeki etkisinin incelenmesi (Doktora Tezi). Gazi Üniversitesi Beden Eğitimi ve Spor Anabilim Dalı, Ankara

*Özdoğru, K.(2018). 10-12 yas grubu erkek yüzücülerde 8 baftahk dinamike kor antrenmanmm baž motorik özellikler ile $100 \mathrm{~m}$ karşıle stil yü̈me performansina etkisi (Yüksek Lisans Tezi). İstanbul Gelişim Üniversitesi Sağllk Bilimleri Enstitüsü, İstanbul.

*Özgül, B.A. (2019). 17 ve 19 yas grubu futbolcularda uygulanan core ve pliometrik antrenmanlarn bazı motorik özelliklere etkisinin incelenmesi (Yüksek Lisans Tezi). İstanbul Gelişim Üniversitesi/ Sağlık Bilimleri Enstitüsü, İstanbul.

*Sever, O. (2016). Statik ve dinamik core egzersiz çalsmalarmm futbolcularn sïrat ve çabukluk performansina etkisinin karşılaştrrlması (Doktora Tezi). Gazi Üniversitesi/Sağllk Bilimleri Enstitüsü. Ankara.

Abramson, J. H. ve Abramson, Z. H. (2001). Making sense of data. A self instruction manual on the interpretation of epidemiological data. New York: Oxford University Press. 
Akothota, V., Ferreiro, A., Moore,T. ve Fredericson, M. (2008). Core stability exercise principles. Curr Sports Med Rep, $7,39-44$

Aslan, A. K. (2014). Genc futbolcularda sekiz haftalı "core" antrenmanm denge ve fonksiyonel performans üzerine etkisi (Yüksek Lisans Tezi). Selçuk Üniversitesi Sağlık Bilimleri Enstitüsü, Konya.

Borenstein, M., Hedges, L. V., Higgins, J. P. T. ve Rothstein, H. R. (2009). Introduction to meta-analysis. West Sussex-UK: John Wiley \& Sons Ltd.

Boyacı A, Bıyıklı T, (2018). Core antrenmanın fiziksel performansına etkisi: erkek futbolcular örneği. Kilis 7 Aralık Üniversitesi Beden Ë̆itimi ve Spor Bilimleri Dergisi, 2(2), 18-27.

Boyac1, A. (2016). 12-14 yas gurubu çocuklarda merkez bölge (core) kuvvet antrenmanlarmm bazı motorik parametreler üzerine etkisi (Yüksek Lisans Tezi). Muğla Sitkı Koçman Üniversitesi, Sağlık Bilimleri Enstitüsü, Muğla.

Cohen, J. (1988). Statistical power analysis for the behavioral sciences. Hillsdale, NJ: Lawrence Erlbaum Associates.

Cooper, H., Hedges, L. V. ve Valentine, J. C. (2009). The handbook of research synthesis and meta-analysis (2nd Edition). New York: Russell Sage Publication.

Çelik, S. (2013). Illkögretim matematik derslerinde kullanulan alternatif ögretim yöntemlerinin akademik başarya etkisi: Bir meta analiz.çalısması (Yüksek Lisans Tezi). Osmangazi Üniversitesi, Eskişehir

Dinçer, S. (2014). Eğitim bilimlerinde uygulamal meta-analiz: Ankara: Pegem A.

Herrington, L. ve Davies, R. (2005). The influence of pilates training on the ability to contract the transverses abdominis muscle in asymptomatic individuals. Journal of Bodywork and Movement Therapies, 9(1), 52-57.

Kibler, W. B., Press, J. and Sciascia, A. (2006). The role of core stability in athletic function. Sports Medicine, 36(3), 189-198.

Orwin, R. G. (1983). A fail-safe N for effect size in meta-analysis. Journal of educational statistics, 8(2), 157-159.

Petticrew, M. ve Roberts, H. (2006). Systematic reviews in the social sciences. MA-USA: Blackwell Publishers Ltd.

Sağlam, M. ve Yüksel, G. (2007). Program değerlendirmede meta-analiz ve meta değerlendirme. Dumlupinar Üniversitesi Sosyal Bilimler Dergisi, 18(1), 175-188.

Şatıroğlu, S., Arslan, E. ve Atak, M. (2013). Voleybolda core antrenman uygulamaları. 5. Antrenman Bilimi Kongresi. Ankara.

Tse, M. A., Mcmanus, A. M. ve Masters, R. S. (2005). Development and validation of a core endurance intervention program: implications for performance in college-age rowers. The Journal of Strength and Conditioning Research, 19(3), 547-52.

Willardson, J. M. (2014). Developing the core. USA: National Strength \& Conditioning.

Yıldız, N. (2002). Verilerin değerlendirilmesinde meta-analiz̧i (Yüksek Lisans Tezi). Marmara Üniversitesi. İstanbul

\section{EXTENDED ABSTRACT}

In this research, we have done; as a result of the data obtained from the doctorate and master's theses published on The Council of Higher Education thesis center website, the effect of the studies on which the effect of core training on horizontal jump performance is investigated and the results of these studies are presented as a whole with this combining method. Meta-analysis; It is the way to combine the results of multiple studies, which are previously independent, completely independent from each other, and to make a statistical analysis of the research findings obtained and to interpret them and to produce a new result and express this as the effect size value (Lipsey, \& Wilson, 2000).

It is considered that the studies to be included in the research are within certain criteria. These criteria are; having a postgraduate thesis, including experimental and control groups, pretest and posttest data were taken, arithmetic mean and standard deviation data are included. Studies without these criteria are not included in this study. The studies are defined with the following keywords; "Training, core training, core". 15 postgraduate thesis studies examining the effect on core training and horizontal jump performance have been reached. The data of 3 theses are excluded from the study because they do not contain data that meet the specified criteria. As a result of the screening made within the specified criteria, 2 doctoral theses and 10 master theses have been reached. These postgraduate theses are theses published between 2014-2019. The total number of samples within the scope of the studies is 415. A coding form was created in the Microsoft Excel program based on the horizontal leap findings of these studies. This form belongs to the horizontal jump performance; Pretest and posttest data, arithmetic means, standard deviations, sample numbers, sports branches, age of the experiment and control group subjects, type of publication, year of study, author of the study were recorded.

Comprehensive Meta-Analysis (CMA) program was used in experimental meta-analysis. In our study, both fixed effects and random effects model results are encapsulated. In this analysis method, where the effect size is calculated depending on the experimental and control groups, the effect size means the standardized average difference between the groups (Malofeeva, 2005 cited in: Çelik, 2013, p. 58). Interpretations of the effect sizes obtained as a result of meta-analysis were made using Cohen's (1988) effect size classification table. 
In meta-analysis studies, it is important to determine whether there is bias before publishing the effect sizes. If the studies in determining the bias of the publication are included in the funnel and show a symmetrical distribution around the average effect size, it indicates that there is no bias of the publication. Orwin's Error Protection Number is N (Orwin's Fail Safe N), which is used as another method for publication bias detection. Therefore, in order to show whether there is bias in our study, funnel scatter plot and Orwin's Error Protection Number N (Orwin's Fail Safe N) were tested. According to the results of our study, it can be said that there is no publication bias in our study. According to the heterogeneity test, the analysis should be done according to the random effects model and if the heterogeneity is high, a moderator analysis should be performed. It shows the heterogeneity status, $25 \%$ low heterogeneity in the interpretation of $\mathrm{I}^{2}$ value, $50 \%$ moderate heterogeneity and, 75\% high heterogeneity (Cooper et al. 2009, p. 263). In our study, since the level of heterogeneity was very close to medium level $(72,756)$, the results of the mode of publication and the duration of the training were included. According to the results of the moderator analysis of the training period, there was no significant difference between the groups; in the light of the results of the publication type moderator analysis, there was a significant difference in the effect size value between the groups. The significant difference in the moderator analysis is to show that it is one of the sources of heterogeneity effect size. In the study conducted by us, determining a significant difference in the type of publication can be presented as the source of heterogeneity in our study.

Finally; According to the meta-analysis data of this study, when we look at the effect of core training on horizontal jump performance, it is found at the level of 0.372 with a small level $(0.15 \leq \mathrm{d}<0.40=$ small level $)$ and in the random effects model with medium size of $0.473(0.40 \leq \mathrm{d}<0.75=$ medium level). It can be said that core training is moderately effective for the development of horizontal jump characteristics. Therefore, it may be recommended for athletes and coaches to prefer the core training method, although it is not a serious effect if the athletes' change in horizontal jump performance is desired.

Especially in recent years, it is seen that many studies have been conducted examining the effect of core training on performance parameters. In this study, it is thought that it will be important in terms of making a more general judgment about the results of these studies. There is no previous research showing the effect size of core training on horizontal jump performance with the meta-analysis method. Since no previous study has been done on this subject; this study is thought to make important contributions to the literature. The studies that will be done next can be discussed as the subject of research by meta-analysis method on the effect of core training on different parameters such as speed, vertical jump, back muscle strength, leg muscle strength, flexibility, and balance. These studies will provide trainers and athletes with information about how effective core training is for the development of these parameters. Athletes and coaches can also plan their training programs considering these results. 